\title{
DERECHOS SOCIALES, PROTECCIÓN DE LA SALUD E INTERPRETACIÓN CONSTITUCIONAL*
}

\section{ConstanZa SALgado M.**}

RESUMEN: El artículo se divide en dos partes. La primera es una crítica a las comprensiones de los derechos sociales que nos llevan a entenderlos como mínimos sociales. La propuesta de este artículo es que su correcto sentido nos exige una comprensión distinta: los derechos sociales se encarnan en instituciones de ciudadanía, que hacen posible el acceso universal e igualitario a ciertas prestaciones que son esenciales para el desarrollo humano. La segunda parte pretende impugnar la comprensión de que el derecho a la protección de la salud, tal como se encuentra consagrado en la Constitución, exige una estructura sanitaria equivalente a la que configura el régimen legal actual, con un sistema privado de seguros individuales y un sistema público de seguro social. La propuesta de este artículo es que una correcta interpretación de la Constitución permite y posibilita la configuración de un seguro social universal de salud, financiado con las cotizaciones de todos.

PALABRAS CLAVE: Derechos sociales - escasez - derecho a la protección de la salud - interpretación constitucional.

\section{SOCIAL RIGHTS, HEALTH PROTECTION AND CONSTITUTIONAL INTERPRETATION}

ABSTRACT: The article is divided in into two parts. The first part is a critique of some usual conceptualizations of social rights that conceive them as social minimums. In this first part, arguments in favor of different interpretations are established: social rights are embodied in citizenship institutions, which allow for universal and equal access to certain benefits that are essential for human development. The second part of the

Fecha de recepción: 25 de agosto de 2014.

Fecha de aceptación: 25 de noviembre de 2014.

** Licenciada en ciencias jurídicas y sociales, Universidad de Chile (CHile), Magíster en derecho, Pontificia Universidad Católica de Chile (Chile). Profesora de la Universidad Adolfo Ibánez (CHILE). Correo electrónico: constanzasalgadom@gmail.com, constanza.salgado@ uai.cl 
article seeks to challenge the argument that the right to health care, as enshrined in the Chilean Constitution, requires a healthcare system such as the one of the current legal regime, which combines a private system of individual insurance and a public social insurance system. The purpose of this second part is to show that the best interpretation of the Constitution allows and enables the configuration of a universal social health insurance system funded by universal contributions.

KEY WORDS: Social rights - scarcity - right to health care - constitutional interpretation.

Sumario: Introducción. 1) Los derechos sociales como minimos y los derechos sociales como instituciones de ciudadanía. (1.1.) Derechos sociales, escasez y mercado. (1.2.) Derechos sociales como derechos exigibles. (1.3.) ¿Cuál es el sentido de los derechos sociales? (1.4.) Derechos sociales como derechos de ciudadania. (1.5.) El derecho social a la protección de la salud y la configuración de un sistema universal. 2) La protección de la salud y la interpretación de la Constitución. (2.1.) El sistema de salud actual. (2.2.) El derecho a la protección de la salud y su interpretación dominante. Entre el originalismo y el finalismo. (2.3.) La interpretación posible del derecho a la protección de la salud. (2.3.1.) El sistema privado y la inexistencia del deber de fomentarlo. (2.3.2.) Los privados como colaboradores del Estado. (2.3.3.) Las cotizaciones y su destino público. Conclusiones

\section{INTRODUCCIÓN}

Como sabemos, la salud tiene un efecto central en las oportunidades que tienen disponibles las personas. Es este efecto en las oportunidades lo que distingue a la salud (y a la educación) de otros bienes que también mejoran o tienen directa relación con la calidad de vida de los individuos. Como correctamente seńala Normal Daniel, los impedimentos al normal funcionamiento que se producen por los males o enfermedades que nos acechan constituyen restricciones fundamentales al rango normal de oportunidades que están abiertas para cada persona, dadas sus habilidades y talentos ${ }^{1}$. Proteger la salud contribuye a proteger las oportunidades, así

Daniel, Norman (2008) Just Health: Meeting Health Needs Fairly. New York: Cambridge University Press, 397 pp. Este es el punto central del capítulo 1 y 2 del libro. El argumento es básicamente el siguiente: dado que el cuidado de la salud promueve la salud (o el normal funcionamiento) y puesto que la salud contribuye a la protección de las oportunidades de desarrollo de cada uno, entonces el cuidado de la salud protege las oportunidades. Según Daniel, esto hace de los cuidados sanitarios un bien de especial importancia en una sociedad 
como también la habilidad de la gente para participar en la vida política, social y económica que ofrece la vida en sociedad.

Ahora bien, es indudable que para gozar de salud se requiere mucho más que cuidados médicos o prestaciones sanitarias. En efecto, hay un sinnúmero de "determinantes sociales" que influyen en la calidad y tiempo de vida de las personas ${ }^{2}$. Lo notable es que ni siquiera el acceso universal a cuidados sanitarios elimina la asociación entre estatus socioeconómico (como determinante social) y salud: mientras más rico eres más larga y saludable es tu vida ${ }^{3}$. La protección de la salud por sí sola no quiebra el vínculo entre estatus social y salud: la salud de una persona no está absolutamente determinada por las posibilidades de acceso a cuidados sanitarios. Ahora bien, esto no significa que las prestaciones sanitarias no sean una condición necesaria, simplemente hay que tener en cuenta que no son suficientes para eliminar las inequidades en salud. En gran medida, la salud es un asunto mucho más global que se relaciona con la justicia de las sociedades.

que pretende ser justa, en la medida en que la justicia, o al menos la justicia en la comprensión de Rawls, exige la protección de las oportunidades de cada individuo.

2 Las desigualdades sociales y económicas producen desigualdades en salud. La distribución de bienes importantes como educación, vivienda, trabajo, ingresos, oportunidades entre diversos grupos ya sea por razones de raza, género, clase tiene evidentes consecuencias en la salud de la población. Esta vinculación entre salud y condiciones sociales ha sido tematizada no solo en la teoría sino también en la práctica. La Organización Mundial de la Salud (OMS), por ejemplo, entrega bastante información al respecto en http://www.who.int/ social_determinants/en/. Ahora bien, en respuesta a las inequidades persistentes y cada vez mayores, la Organización Mundial de la Salud estableció en 2005 la "Comisión sobre Determinantes Sociales de la Salud", para que ofreciera asesoramiento respecto a la manera de mitigarlas. En el informe final de la Comisión, publicado en agosto de 2008, se proponen tres recomendaciones generales: (1) mejorar las condiciones de vida cotidianas; (2) luchar contra la distribución desigual del poder, el dinero y los recursos; (3) medición y análisis del problema. Véase el informe de la Comisión en: http://apps.who.int/gb/ebwha/pdf_files/ A62/A62_R14-sp.pdf?ua=1. Respecto al tema de los determinantes sociales puede verse un interesante artículo: Daniel, Norman; Kennedy, Bruce; Kawachi, Ichiro (1999) "Why justice is good to our health: the social determinants of health inequalities". Daedalus, Vol. 128, No. 4, Bioethics and Beyond, pp. 215-251.

3 Por ejemplo, también puede asociarse a la etnia o la raza. Así, los blancos tienen mejor salud que los negros en Estados Unidos. Esto por ejemplo, lo nota Daniel en un párrafo que, pese a lo extenso, vale la pena citar: "En todas las sociedades nos encontramos con un "gradiente social" de la salud. Si graficamos la esperanza de vida, una medida aproximada de la salud, o la esperanza de vida saludable vinculándola con la situación socioeconómica de las personas, nos encontramos con que son los más ricos (y, en los Estados Unidos, los blancos) las personas que tienen vidas más saludables y extensas. Diferentes países tienen gradientes más pronunciados o más planos, dependiendo de muchos factores relativos a la distribución que hacen de otros bienes, como la educación, los ingresos, la riqueza, la vivienda y el acceso a la atención médica. En los Estados Unidos, cuando la salud se vincula a las desigualdades en los ingresos, la educación y la cobertura del seguro, todavía encontramos desigualdades raciales significativas en la esperanza de vida y la morbilidad. Desigualdades similares entre los grupos raciales y étnicos se pueden encontrar en muchos países”. DANIEL (2008) 14. 
Por ahora la idea no es evaluar las estructuras sociales que atentan contra la mala salud de las personas. El objeto es más modesto: es evaluar qué exige de nosotros el derecho social a la protección de la salud, teniendo en cuenta que la salud preserva nuestro estatus de ciudadanos en la medida en que protege nuestras oportunidades de desarrollo.

La propuesta de este artículo es que los derechos sociales exigen más que un mínimo que simplemente ampare a quienes no pueden pagar por prestaciones en el mercado. Criticando las comprensiones de los derechos sociales que nos llevan a entenderlos como mínimos sociales, se propone una comprensión distinta: los derechos sociales nos exigen configurar instituciones de ciudadanía, que hagan posible el acceso universal e igualitario a ciertas prestaciones que son esenciales para el desarrollo humano. La segunda parte de este artículo, de la mano de lo señalado en la primera, hace una crítica a la interpretación común de la disposición constitucional que consagra el derecho a la protección de la salud, en la medida en que considera que la Constitución no solo permite sino que exige la configuración de un sistema sanitario como el actual.

\section{1) LOS DERECHOS SOCIALES COMO MÍNIMOS Y LOS DERECHOS SOCIALES COMO INSTITUCIONES DE CIUDADANÍA}

Hoy en día es dominante la idea de que los derechos sociales solo pretenden reparar las consecuencias brutales de la pobreza "salvando" a los que están peor. De acuerdo a esta idea, la intervención del Estado es necesaria, mas solo a través de servicios públicos de carácter asistencial que garanticen un mínimo necesario a quienes fracasan en la obtención de las prestaciones que ofrece el mercado. Esta se ha vuelto la comprensión paradigmática de los derechos sociales: se trata de una que los entiende simplemente como mínimos sociales ${ }^{4}$.

Esta comprensión de los derechos sociales como mínimos se debe, a mi entender, a dos formas incorrectas de entender los derechos sociales y su sentido.

4 En este sentido, Atria plantea que la tradición liberal y el derecho burgués solo puede entender los derechos sociales como derechos a un mínimo. La estructura del derecho burgués es la del derecho privado, es decir, la del derecho subjetivo y esta estructura le impide entenderlos como verdaderos derechos sociales, es decir, como derechos que expresan una manifestación de una forma superior de comunidad, una en que cada uno contribuye de acuerdo a sus capacidades, y recibe de acuerdo a sus necesidades. Véase Atria, Fernando (2004) “Existen derechos sociales?”, pp. 15-59, 4 Discusiones. Disponible en http://www.cervantesvirtual.com/obra/existen-derechos-sociales-0/[fecha de visita 1 de septiembre de 2014]. 


\section{1) DERECHOS SOCIALES, ESCASEZ Y MERCADO}

La primera forma se funda en la (incorrecta) premisa de que cuando se trata de bienes económicos y escasos, no es posible hablar de derechos sociales o solo sería posible contemplar derechos sociales a un mínimo, que tengan por objeto subsidiar a quienes no pueden adquirir en el mercado las prestaciones que ellos implican. En efecto, como se sabe, la forma usual de enfrentar la escasez es el mercado 5 . Y la economía, como disciplina, una forma de resolver el problema de la escasez de la forma más eficiente posible.

Ahora bien, cuando se trata de bienes que involucran derechos sociales, es usual asumir que la forma en que deben asignarse dichos bienes (como salud, educación, vivienda, pensiones, etc.) es de acuerdo a la capacidad de cada uno de pagar por ellos. En este contexto, los derechos sociales asumirían la forma de subsidios para entrar al mercado (complementarias al mercado) o bien prestaciones que vienen a suplirlo. Piénsese en el caso de Chile. Como la educación es algo que puede adquirirse en el mercado, es esta dimensión la que estructura el sistema. Como se sabe, el sistema educativo chileno, se estructura sobre la base de la libertad de los oferentes de servicios educacionales de poder cobrar por los mismos y la libertad de los padres de pagar la cantidad de dinero que corresponda a sus ingresos y su riqueza. Esta no es sino la forma básica de operación que tiene el mercado. Pero como hay algunos que no pueden pagar nada (realmente significativo) por educación, y se trata de un bien importante, es el Estado el que tiene el deber de subsidiarlos para que puedan hacerlo ${ }^{6}$. De esta forma, quienes no tienen cómo pagar la educación asisten a escuelas municipales, donde reciben una educación equivalente a la subvención base (es decir, de 60 mil pesos aproximadamente ${ }^{7}$ ); quienes pueden hacer algún aporte monetario, asisten a las escuelas particulares subvencionadas que exijan el nivel de aporte que esos padres pueden pagar; y finalmente quienes pueden pagar enteramente por la educación de sus hijos, los cuales asisten a colegios particulares pagados. Algo equivalente puede decirse

5 En efecto, si hubiera abundancia, cada uno recibiría lo que deseara, y no habría necesidad de asignar valor a las cosas.

6 De acuerdo al artículo $19 \mathrm{~N}^{\circ} 10$ inciso 5 de la Constitución, "La educación básica y la educación media son obligatorias, debiendo el Estado financiar un sistema gratuito con tal objeto, destinado a asegurar el acceso a ellas de toda la población". Este inciso es el resultado del artículo único de la reforma constitucional de la ley 19876 que establece la obligatoriedad y gratuidad de la educación media. Hasta antes de la reforma la Constitución establecía solo que la educación básica era obligatoria y gratuita.

$7 \quad$ La subvención se expresa en un sistema de cuentas denominado Unidad de Subvención Escolar (USE), cuyo valor monetario es ajustado periódicamente para compensar por incrementos del nivel de precios. El monto base recibido por alumno varía dependiendo del nivel de enseńanza, de la modalidad y de si está en régimen de jornada escolar completa o no lo está. 
respecto a la salud y las pensiones. En ambos casos, quienes no pueden acceder a los seguros privados que ofrecen las Isapre o que no alcanzan a tener una pensión que permita su subsistencia, tienen disponible tanto un sistema de salud pública y como una "pensión básica solidaria de vejez".

Sin embargo, esta no es solo la forma en que estructuramos las instituciones que concretizan los derechos sociales. Como podrá observarse, para buena parte de la teoría constitucional esa comprensión no es problemática precisamente en la medida en que esta entiende los derechos sociales como derechos del individuo frente al Estado a algo que -si el individuo poseyera medios financieros suficientes y si encontrase en el mercado una oferta suficiente- podría obtenerlo también de los particulares ${ }^{8}$.

Nótese que para un teórico tan conocido en Latinoamérica como Alexy, los derechos sociales son derechos que exigen prestaciones por parte del Estado solo cuando las personas no pueden adquirirlas en el mercado: se trata entonces de derechos subsidiarios, lo que quiere decir que el lugar natural donde deben ser satisfechas las necesidades que esos derechos protegen es el mercado 9 . En efecto, Alexy supone que cuando se trata de "derechos de prestación en sentido estricto", es decir, de bienes y servicios esenciales pero escasos, el mecanismo de asignación adecuado es el mercado, y solo cuando faltan "medios financieros suficientes", debe aparecer el Estado.

En este mismo sentido, Hierro señala que "la filosofía del derecho y del estado que suscribe Alexy parece asumir sin mucha discusión tres axiomas notoriamente conservadores de parte de Alexy”. En lo que ahora nos interesa, el tercer axioma que asume Alexy es que:

los derechos a prestaciones en sentido estricto son derechos a bienes que uno podría adquirir en el mercado si tuviese recursos suficientes. En este tercer axioma se incluye una cierta petición de principio pues se da por supuesto, sin argumento alguno, que un sistema educativo público o un sistema sanitario público solo se justifican como remedio subsidiario para solucionar carencias del lado de la oferta o del lado de la demanda mientras que es perfectamente argumentable que se justifican para satisfacer derechos fundamentales y que es la iniciativa privada la que tiene un mero papel subsidiario en la creación de estos servicios, papel que puede justificarse en base al principio de libertad de empresa y, en el caso de la educación, al principio de libertad ideológica $^{10}$. Constitucionales, 607 pp., p. 482.

9 Por supuesto, esto no significa que la titularidad de los derechos no sea universal, sino que quienes no pueden acceder a dichos bienes por sus propios medios, tienen siempre la posibilidad de exigirlos al Estado, como titulares de "derechos sociales".

10 Hierro, Liborio (2009) "Los derechos económico-sociales y el principio de igualdad en la teoría de los derechos de Robert Alexy" en Derechos Sociales y Ponderación. Madrid: Fundación Coloquio Jurídico Europeo, 405 pp., p. 217 (el destacado es mío). 
Esta comprensión de la relación entre prestación y mercado, inevitablemente lleva a Alexy a afirmar que los derechos sociales son derechos a un minimo ${ }^{11}$. Ahora bien, la idea de mínimo aquí no tiene que ver con que el mínimo sea lo necesario para "subsistir" sino que minimo en relación a la cantidad y calidad del mismo bien o servicio que se puede obtener en el mercado. El mínimo puede ir subiendo llegando incluso a ser alto, pero es minimo en la medida en que nunca puede ser más atractivo que el mercado. La razón es que es incompatible que el Estado preste subsidiariamente bienes o servicios a quienes no alcanzan a obtenerlos en el mercado y, que al mismo tiempo, lo haga a través de prestaciones iguales o superiores a las que este ofrece, ya que en tal caso el mercado devendría irrelevante. Bajo esta comprensión los derechos sociales tendrían un límite preciso y determinado en relación a las prestaciones que garantizan: estas tendrían que estar siempre por debajo de las que el mercado ofrece.

\section{2) DERECHOS SOCIALES COMO DERECHOS EXIGIBLES}

Sin embargo, no solo esta vinculación entre derechos sociales, escasez y mercado transforma tales derechos en mínimos sociales. La comprensión de los derechos sociales como derechos subjetivos, es decir, como derechos exigibles ante tribunales ${ }^{12}$ es la segunda forma de entenderlos que termina reduciéndolos a un mínimo.

Para observar de manera prístina por qué ocurre esto nada mejor que volver sobre Alexy, ahora no sobre su comprensión de la relación entre mercado y derechos, sino sobre su propuesta teórica-metodológica. En efecto, su teoría de los derechos fundamentales también lo lleva a este resultado, en la medida que esta tiene como punto de referencia constante el control por parte de los tribunales de todo acto que pudiere afectar derechos fundamentales. Bajo este enfoque de control judicial, ¿cómo se determina qué políticas los tribunales pueden cuestionar sin atentar contra el principio democrático? Según Alexy, con el objeto de dejar espacio

11 Véase en la nota 17 cómo es que Alexy expresamente señala que los derechos sociales se hacen exigibles cuando se trata de "derechos fundamentales sociales mínimos, es decir, por ejemplo, a un mínimo vital, a una vivienda simple, a la educación escolar, a la formación profesional y a un nivel estándar mínimo de asistencia médica”.

12 María Beatriz Arriagada en un excelente trabajo explica cómo es que el concepto de "derecho subjetivo" al menos en la formulación canónica de Kelsen y Hohfeld no contiene como elemento central su accionabilidad ante tribunales. Arriagada, María Beatriz (2012) "Los derechos sociales: únicos derechos fundamentales". En Aguilar, Gonzalo (editor): Los derechos Económicos, Sociales y Culturales en el orden constitucional chileno. Santiago: Librotecnia, pp. 61-91. El punto en este artículo, sin embargo, no es conceptual, sino más bien asociativo. Por esto está en concordancia con lo que seńala Arriagada, que precisamente muestra que, cuando se quiere enfatizar que los derechos sociales son justiciables ante tribunales, usualmente se hace referencia ellos como "derechos subjetivos". 
al legislador ${ }^{13}$, los tribunales solo tienen competencias para controlar las políticas legislativas cuando estas están por debajo del mínimo social exigible. Alexy afirma que este mínimo es el resultado de una ponderación de todos los valores que podrían estar involucrados ${ }^{14}$ : para que proceda la prestación por parte del Estado esta debe ser requerida por el principio de libertad fáctica, y tanto el principio democrático como los principios opuestos no deben ser afectados sino "en una medida relativamente reducida"; solo entonces cabe admitir que dicha prestación social está garantizada por la constitución ${ }^{15}$. Según Alexy, tales condiciones se satisfacen "en el caso de los derechos fundamentales sociales minimos, es decir, por ejemplo, a un minimo vital, a una vivienda simple, a la educación escolar, a la formación profesional y a un nivel estándar minimo de asistencia médica" 16.

Como se observa, este aspecto metodológico que subyace a la teoría de Alexy estructura su comprensión de los derechos sociales, juridificándolos: lo que los derechos sociales exigen es lo jurídicamente exigible; lo exigible jurídicamente es lo accionable ante tribunales; y lo accionable ante tribunales es lo minimo, de otra forma se atenta contra el principio democrático. Bajo esta comprensión, los derechos fundamentales sociales deben entenderse entonces como derechos sociales mínimos ${ }^{17}$. En efecto, la juridificación (vía accionabilidad) pareciera que inevitablemente lleva a una comprensión mínima de los derechos sociales o, en otros términos, a

13 Nótese que esa es la objeción de Böckenforde a la cual Alexy intenta responder en su famoso Epílogo a su libro "Teoría de los Derechos Fundamentales".

14 Así, según Alexy, "Habrá que considerar que una posición de prestación jurídica está definitivamente garantizada iusfundamentalmente si (1) la exige muy urgentemente el principio de la libertad fáctica y (2) el principio de la división de poderes y de la democracia (que incluye la competencia presupuestaria del Parlamento) al igual que (3) principios materiales opuestos (especialmente aquellos que apuntan a la libertad jurídica de otros) son afectados en una medida relativamente reducida. En todo caso estas posiciones están satisfechas en el caso de los derechos fundamentales sociales mínimos, es decir, por ejemplo, a un mínimo vital, a una vivienda simple, a la educación escolar, a la formación profesional y a un estándar mínimo de asistencia médica”. Alexy (1993) 495.

15 Así, según Alexy, "de acuerdo con el modelo, el individuo tiene un derecho definitivo a la prestación cuando el principio de la libertad fáctica tiene un peso mayor que los principios formales y materiales opuestos tomados en conjunto. Este es el caso de los derechos mínimos”. Alexy (1993) 495.

16 Según Hierro, todos los derechos fundamentales tienen una dimensión de "derechos de prestación” por lo que al fin de cuentas todos los derechos solo serían controlables cuando la legislación se sitúa bajo un mínimo constitucionalmente inadmisible. Hierro (2009).

17 Ahora bien, el establecimiento de los derechos sociales en la constitución no implica dotarlos de accionabilidad. No hay relación necesaria entre constitución y accionabilidad o justiciabilidad y por tanto no la conclusión de una comprensión que rechaza la justiciabilidad de los derechos sociales no tiene por qué ser una que rechaza su inclusión en la constitución. En esta línea, el hecho de que los derechos sociales no sean justiciables no significan que carezcan de sentido relevante. 
una comprensión de los derechos sociales como si se tratase de derechos individuales $^{18}$.

Ahora bien, ¿por qué los derechos sociales se terminan comprendiendo como si fuesen derechos individuales? Esto ocurre, básicamente, porque con el objeto de dotarlos de la misma importancia que a los derechos civiles, activistas, doctrina y tribunales se afanan en equipararlos: la característica central de ambos tipos de derechos es que serían derechos subjetivos, es decir, derechos que otorgan a su titular una acción para reclamar ante tribunales el cumplimiento de una obligación correlativa ${ }^{19}$. Esta perspectiva, por lo demás, es la comprensión de los derechos sociales de gran parte de la teoría constitucional latinoamericana ${ }^{20}$.

El problema es que el reclamo y la decisión judicial que lo concede transforman el derecho "social" en una demanda que tiene por objeto satisfacer una pretensión "individual" y en una decisión que si pretende seguir siendo jurisdiccional y no política, tiene como marco solo el interés individual que se reclama en la demanda. De este modo, señala Atria en ¿Existen derechos sociales?,

"el derecho social a la protección de la salud, que originalmente consistía en que se garantizara un nivel de atención de salud a todos... se convierte en un derecho individual alegado por el demandante de que se obligue al Estado a dar una determinada prestación de salud, sin que las necesidades de los otros puedan ser relevantes... Lo que llega al tribunal no es un derecho social, no puede ser un derecho social, sino una demanda privada, que expresa ya no la idea de una forma superior de comunidad sino la negación de esta: la pretensión del deman-

18 Cuando se señala que los derechos sociales se terminan comprendiendo como derechos individuales no se está diciendo que los bienes que los derechos sociales garantizan solo pueden gozarse colectivamente. Los bienes a que los derechos sociales protegen, por supuesto se gozan individualmente.

19 La comprensión canónica del término derecho subjetivo no solo hace referencia a la idea de deber como correlativo al derecho sino que también a la posibilidad de reclamar ante tribunales el cumplimiento de dicho deber por parte del destinatario. Así, véase por ejemplo Kelsen en su Teoría Pura del Derecho.

20 En Latinoamérica véase a Ruiz Miguel, Alfonso (1994) "Derechos liberales y derechos sociales” (Doxa15-16), pp 651-674. Disponible en http://www.cervantesvirtual.com/obra/ derechos-liberales-y-derechos-sociales-0/[fecha de visita 1 de septiembre de 2014]; ABRAHImovich, Víctor; Courtis, Christian (2002) Los derechos sociales como derechos exigibles, Madrid: Trotta, 254 pp. En Chile, véase por ejemplo a Bustos, Rodrigo (2009) "Derechos sociales y recurso de protección: ¿una relación difícil?”. Derecho y Humanidades, No 15, pp. 231-247; Figueroa, Rodolfo (2009) "Justificación del rol de las cortes haciendo justiciables los derechos económicos, sociales y culturales, en particular, el derecho a la protección de la salud”. Revista Chilena de Derecho, vol. 36 N $^{\circ}$ 2, pp. 313-342. Disponible en http://www. scielo.cl/scielo.php?script=sci_arttext\&pid=S0718-34372009000200005 [fecha de visita 1 de septiembre de 2014]. 
dante de que su interés sea atendido, aun a costa del interés de los demás" 21 .

Ahora bien, nótese cómo esta crítica a la común comprensión latinoamericana de los derechos sociales como derechos subjetivos, y por tanto, como derechos justiciables, no tiene su foco de atención en el problema de la distribución de competencias que los derechos sociales plantean ni en la mayor legitimidad democrática del Poder Legislativo frente al Poder Judicial al momento de decidir sobre las políticas sociales que implican recursos públicos ${ }^{22}$. Es una crítica mucho más profunda. Su objeto es mostrar que la comprensión de los derechos sociales como derechos subjetivos (accionables) transforma su identidad de derechos "sociales" en una de derechos "individuales": el precio de la equiparación es su transformación.

La razón, es que la noción de derecho subjetivo es incapaz de contener en su estructura las exigencias que los derechos sociales plantean: su pretensión apela a una exigencia de justicia distributiva que no puede ser contenida por la estructura de los derechos subjetivos que apela a una lógica conmutativa (propia del derecho privado). Michelon entiende claramente este punto cuando señala que cuando se trata de derechos sociales, el foco es que cuestiones de justicia distributiva, i.e. cuestiones sobre cuáles son los criterios generales de tratamiento igualitario a ser utilizados en distribuciones entre los miembros de una comunidad, son cuestiones que no pueden ser jamás decididas por intermedio de argumentos puramente juridicos. Para decir lo mismo con otras palabras: una forma de razonamiento que es orientada hacia la justicia entre privados (i.e. una justicia de tipo correctivo) no puede ser utilizada como forma de razonamiento para la realización de la justicia distributiva ${ }^{23}$.

Como se ve, la judicialización de los derechos sociales contenida en la pretensión de que se trata de derechos subjetivos termina atentando contra su propia lógica, ya que los transforma, inevitablemente, en derechos individuales ${ }^{24}$. La razón, como hemos visto, es que los tribunales no están en la mejor posición para determinar de manera adecuada cómo de-

21 Atria (2004) 46. Nótese que cuando Atria señala que "lo que llega al tribunal no es un derecho social, no puede ser un derecho social, sino una demanda privada", no se está refiriendo a derechos colectivos sino a la forma en que cuando un derecho social se exige ante tribunales termina entendiéndose: como el derecho a una prestación específica, concreta e individual.

22 La razón usual para rechazar la judicialización de los derechos sociales tiene que ver con el argumento democrático.

23 Michelon, Claudio (2004) “Introducción: derechos sociales y la dignidad de la igualdad”, en 4 Discusiones, pp. 7-13. Disponible en http://www.cervantesvirtual.com/obra/introduccin-derechos-sociales-y-la-dignidad-de-la-igualdad-0/[fecha de visita 1 de septiembre de 2014], p. 12.

24 Que como derechos constitucionales no sean exigibles ante tribunales no significa que una vez que se legalizan no hayan acciones para reclamar las prestaciones establecidas. 
ben distribuirse los recursos escasos, no por falta de legitimidad democrática o por un déficit institucional que nubla su perspectiva, sino porque "los tribunales, en la medida en que razonan como tales, es decir sobre la base de derechos subjetivos, no son instituciones aptas para implementar una repartición verdaderamente igualitaria de bienes como la salud, la educación, y otros que son objeto de derechos sociales"25.

\section{3) ¿CUÁl ES EL SENTIDO DE LOS DERECHOS SOCIALES?}

Como se observa, el énfasis en comprender los derechos sociales como derechos subjetivos (y por tanto, en señalar que son estructuralmente idénticos a los derechos civiles) niega la exigencia distributiva que contienen. Por otro frente, la incuestionable premisa de que como su objeto consiste en bienes económicos escasos es el mercado la forma primaria de asignarlos, hace que se terminen concibiendo como derechos subsidiarios, mínimos. Lo que me interesa resaltar es que ambas comprensiones de los derechos sociales inevitablemente llevan a entenderlos como derechos a prestaciones mínimas, no como derechos cuyo sentido reclama una distribución que abra iguales oportunidades de desarrollo para todos.

El sentido de los derechos sociales no es el de exigencias de prestaciones básicas que garantizan que quienes no pueden obtener con sus recursos ciertos bienes en el mercado, al menos puedan obtener ciertos mínimos de parte del Estado. Por el contrario, los derechos sociales son, precisamente, una forma de enfrentar la escasez radicalmente distinta a la que el mercado propone. Ahora bien, por eso mismo, los derechos sociales no son afirmaciones "voluntaristas" que niegan la escasez, sino que constituyen, precisamente, una forma distinta al mercado de afrontarla. ¿Qué significa esto? Significa que los derechos sociales son un mecanismo de distribución alternativo al mercado. Como se sabe, en el mercado, cada uno obtiene lo que puede pagar. Sin embargo, cuando se trata de derechos sociales cada uno recibe, en principio, de acuerdo a criterios igualitarios. Esto no significa, por supuesto, negar la escasez o asumir que se trata de recursos ilimitados; ni tampoco significa asumir que se debe dar a todos lo mismo. Esa es una incorrecta forma de entender la igualdad. Respecto al ideal de igualdad es importante descartar las tesis que equiparan la igualdad al uniformismo, a una igualdad de recursos insensible a las diferentes necesidades de cada uno o a la igualdad material absoluta. Esos contenidos no forman parte de la igualdad como ideal. La igualdad, como ideal, no es sino la posibilidad de que realización personal no sea el privilegio de unos pocos, sino que esté disponible para todos. La igualdad, su

25 Michelon (2004) 10. 
sentido, no tiene que ver con distribución económica uniforme, sino con la posibilidad de que el pleno desarrollo esté disponible para todos y no sea el privilegio de unos pocos.

De esta forma, los derechos sociales son un modo distinto de enfrentar la escasez, y entonces pueden ser entendidos no como derechos a prestaciones específicas y determinables ex ante, sino como un criterio de distribución igualitario y por tanto, alternativo al mercado. Ahora bien, ¿de dónde surge este criterio? Este es un punto importante, por cierto. Porque los derechos sociales son derechos y no solamente un criterio que permite diseñar instituciones justas, en el sentido que podría darle una teoría de la justicia.

\section{4) DERECHOS SOCIALES COMO DERECHOS DE CIUDADANÍA}

En primer lugar, es correcto que cuando hablamos de derechos hacemos referencia a deberes correlativos. Ahora bien, ¿cuáles son estos deberes que los derechos nos demandan? La represión de una manifestación, la tortura, el matar a otro, la denegación de justicia son todas acciones que constituyen claramente un incumplimiento de deberes, y por tanto, una violación de ciertos derechos.

Cuando se trata de una deficiente protección de la salud, por el contrario, no sabemos bien qué deber se incumple o si dicha conducta implica o no una violación del derecho a la protección de la salud. La razón es que a diferencia de lo que ocurre con los derechos individuales, de los derechos sociales no se derivan mandatos de conducta directos y determinados dirigidos a todos. El derecho a la protección de la salud no impone un mandato directo de aliviar el dolor del que sufre o del enfermo, por ejemplo ${ }^{26}$. Los derechos sociales no implican mandatos directos, determinados e individuales dirigidos a individuos o al Estado ${ }^{27}$ : es obvio que alguien que sufre una enfermedad al corazón puede necesitar un trasplante de corazón como una "necesidad básica” en el sentido de que sería esencial para su supervivencia ${ }^{28}$. Sin embargo, no podemos llegar a la

26 Véase Singer, Peter (1972) "Famine, affluence, and morality". Philosophy and Public Affairs, Vol. 1, N³, (Spring), pp. 229-243. En Chile, esta postura la ha defendido ZúñIgA, Alejandra (2009) "Más allá de la caridad". Revista de Derecho de la Pontificia Universidad Católica de Valparaiso, XXXIII, pp. 621-638. Disponible en http://www.scielo.cl/pdf/rdpucv/n33/ a17.pdf [fecha de visita 1 de septiembre de 2014].

27 Los derechos sociales pueden concretizarse en mandatos directos, determinados e individuales cuando se trata de exigencias minimas que pueden reclamarse ante el Estado, como por ejemplo, cuando se puede reclamar educación escolar gratuita, que el Estado la presta en base a sostenedores municipales y una subvención escolar educacional.

28 Eleftheriadis, Pavlos (2012) "A Right to Health Care". The Journal of Law, Medicine and Ethics, Volume 40 Issue 2, Summer, pp. 268-285, p. 274. 
conclusión de que solo por esta razón esta persona tiene derecho a dicho trasplante.

Frente a la verdad de esta afirmación, algunas teorías proponen adoptar una perspectiva "instrumental" de los derechos sociales. De acuerdo a esta comprensión, los derechos aseguran el acceso a algo bueno y tienen valor en la medida en que logran alcanzar ese algo ${ }^{29}$. Así, por ejemplo, podemos decir que tiene que haber un derecho a la alimentación si la comida es una buena cosa, o un derecho a la protección de la salud, dado que la salud es una buena $\cos ^{30}$.

Pareciera entonces que los derechos individuales deben entenderse como imponiendo deberes o mandatos directos a las personas y, en cambio, los derechos sociales como medios para el logro de aspiraciones $\mathrm{u}$ objetivos sociales de acceso a ciertos bienes importantes. Sin embargo, los derechos sociales no son meramente un medio para el acceso a bienes que se considera importantes. Tanto los derechos "individuales" como los "sociales" son derechos relacionales; ambos configuran relaciones entre las personas y dotan de un significado común a nuestras acciones. La tortura, por ejemplo, no está mal por el dolor que causa, sino por la actitud que expresa. Detener la tortura no se limita a apuntar detener el dolor del torturado. La tortura es inadmisible, ya que muestra un profundo desprecio por la dignidad del otro ser humano ${ }^{31}$. Así, el derecho contra la tortura no es solo un medio para el alivio del sufrimiento. La diferencia entre derechos sociales e individuales, sin embargo, está en el tipo de relación que estos derechos expresan. Los derechos individuales expresan nuestro reconocimiento mutuo como agentes libres; los derechos sociales expresan nuestro reconocimiento mutuo como ciudadanos.

Ahora bien, esta diferencia se manifiesta también en la forma en que se expresa esa relación. Los derechos individuales imponen deberes de conducta directos a las personas; los derechos sociales, por su parte, el deber de establecer instituciones que hagan posible el reconocimiento y el ideal de igualdad de la ciudadanía ${ }^{32}$.

29 Eleftheriadis (2012) 270.

30 ELEFTHERIADis (2012) 272.

31 Los derechos individuales implican prohibiciones de afectación de lo que esos derechos protegen, los derechos sociales no implican prohibiciones directas: pero sí el pago de impuestos, por ejemplo.

32 Hay dos ideas centrales del concepto de ciudadanía que deben tenerse en cuenta. La primera, tiene que ver con que la idea de ciudadanía, a diferencia de la idea de "agente de mercado" o "individuo", hace referencia directa a un vínculo; vínculo interpersonal que da forma a una comunidad. Ahora bien, como todo vínculo, el de ciudadanía contiene un conjunto de derechos y obligaciones recíprocas. Lo interesante, y aquí a mi entender está la segunda idea central, es que dichos derechos y deberes no están predefinidos ni determinados, porque la ciudadanía es una idea que se desarrolla a lo largo de la historia. Como señalara Marshall en su famoso libro "Ciudadanía y Clase Social": la ciudadanía es aquel estatus que se concede a los miembros de pleno derecho de una comunidad. Sus beneficiarios son 


\section{5) EL DERECHO SOCIAL A LA PROTECCIÓN DE LA SALUD Y LA CONFIGURACIÓN DE UN SISTEMA UNIVERSAL}

Los derechos sociales, entonces, contienen un criterio de distribución igualitario, paralelo al mercado. La razón es que el deber que los mismos exigen es el diseño de instituciones que encarnen nuestro igual status como ciudadanos.

Esta comprensión de los derechos sociales no es nueva. Por el contrario, no es sino el rescate de la forma en que han sido concebidos al interior de la tradición socialdemócrata: no como derechos subjetivos (en el sentido de accionables ante tribunales) ni como subsidios mínimos paralelos al mercado, sino como la afirmación de la posibilidad de igualdad en ciertos ámbitos cruciales de nuestro bienestar como ciudadanos. Bajo esta comprensión, un sistema de derechos mínimos, expresa un desinterés incompatible con nuestro vínculo como ciudadanos ${ }^{33}$.

Es así como los derechos sociales se encarnan en instituciones de ciudadanía. En instituciones que, por reconocer el igual estatus de todos, atiendan las necesidades imprescindibles para el desarrollo de cada uno, desvinculando acceso y asignación (distribución) de su pago (contribución). ¿Qué instituciones permiten esto? La respuesta, nuevamente, no es novedosa (al menos en la tradición socialdemócrata). Se trata de instituciones configuradas como sistemas prestacionales universales financiados con impuestos.

En esta nueva comprensión, los derechos sociales ya no son una manera de asegurar prestaciones mínimas a quien no puede acceder a ellas en el mercado. De hecho, ya no complementan el mercado permitiendo el acceso a aquellos que no pueden hacerlo por sus medios. Ahora lo niegan. Bajo esta nueva comprensión los derechos sociales suponen el principio precisamente contrario al de exclusión, propio del mercado: se trata del principio universalista. De acuerdo a este principio, el acceso y calidad de las prestaciones no

iguales en cuanto a los derechos y obligaciones que implica. Aunque no existe un principio universal que determine cuáles son los derechos y obligaciones, las sociedades donde la ciudadanía es una institución en desarrollo crean la imagen de una ciudadanía ideal que sirve para calcular el éxito y es objeto de las aspiraciones. Marshall, Thomas Humphrey (1992) Ciudadanía y clase social. Madrid: Alianza Editorial, 149 pp.

33 En este sentido, una comprensión mínima de los derechos sociales es una comprensión no desarrollada aún, ya que no logra que estos se integren como parte de los derechos y deberes de ciudadanía. Esta desintegración de derechos sociales y ciudadanía ha permitido que hasta en los ámbitos más básicos y esenciales de la vida se sigan manteniendo las desigualdades propias del mercado. Como diría Marshall bajo una comprensión mínima, los derechos sociales no están integrados en el edificio de la ciudadanía, sino que solo tienen por objeto aliviar las molestias de la pobreza sin alterar el modelo de desigualdad, del que la pobreza por supuesto es el resultado más desagradable. Por esta razón, una comprensión más desarrollada de los derechos sociales exige que estos formen parte integrante de la ciudadanía. Marshall (1992) 61. 
está condicionado a la capacidad de pago de quienes las reciben. Esta desvinculación entre pago y prestación excluye el mercado (como modo de distribución de bienes y servicios). Por su parte, los derechos sociales redefinen la comprensión que tenemos de los impuestos, y por tanto, su justificación. Esta ya no se encuentra en el interés individual de quien los paga. Los impuestos ahora se justifican porque hacen posibles los derechos sociales. $\mathrm{O}$ en términos más amplios, hacen posible que los aspectos centrales del bienestar de las personas (la seguridad, el orden público, el cuidado del medio ambiente, el funcionamiento del mercado, el mantenimiento de las ciudades, la educación, la salud, previsión) no queden condicionados a las posibilidades de pago sino a lo que cada uno necesita.

Esto, por supuesto, no significa que todos tienen derecho a todo negando así la escasez. Es evidente que tratar a la salud como un derecho social no implica que cada uno tenga derecho a todas las prestaciones de salud que desee. Lo que quiere decir es que las prestaciones de salud no han de distribuirse entre todos según lo que cada uno pueda dar a cambio, sino según un criterio cuya aplicación sea consistente con reconocer a todos el mismo derecho. Que el criterio descanse en el igual derecho de todos no implica, por supuesto, que debe dar a todos los mismo. Normalmente esto exigirá la fijación de criterios de acceso que, mirando a la necesidad de atención médica, distribuya entre todos el total de prestaciones escasas. Es decir, el derecho a la salud exige un protocolo público de especificación de las condiciones de necesidad médica que dan acceso a las prestaciones de salud, de modo que todos tengan el mismo acceso a las prestaciones según sus necesidades ${ }^{34}$.

\section{2) LA PROTECCIÓN DE LA SALUd Y LA INTERPRETACIÓN DE LA CONSTITUCIÓN}

¿Admite nuestra Constitución un sistema universal de salud, que desvincule prestación y pago? En Chile, la lucha política por un sistema

34 En un mundo de recursos escasos el establecimiento de prioridades en materia de salud es inevitable. Su establecimiento, no obstante, suele ser objeto de polémica ya que priorizar requiere privilegiar algunas necesidades más que otras igualmente legítimas. En este contexto, es necesario distinguir los "criterios de priorización" de lo que denominamos "mérito". Esta distinción, sin embargo, no siempre es fácil de hacer. Muchas veces, a la hora de determinar prioridades, pareciera razonable atender a características personales, en la medida que las mismas pudieren afectar la capacidad de dichas personas para beneficiarse de las intervenciones médicas. Lo que sucede es que los factores usuales que afectan la capacidad de beneficiarse, como la edad, la discapacidad o el estilo de vida pueden llegar a ser similares a los que determinan el tratamiento sobre la base de merecimiento. En todo caso, aunque sea difícil distinguir es necesario mantener la distinción como criterio. WEALE, Alfred; Clark, Sarah (2012) "Social values in health priority setting: a conceptual framework". Journal of Health Organization and Management, Vol. $26 \mathrm{~N}^{\circ}$ 3, 2012, pp. 293-316, p 307 
de salud universal y solidario estuvo presente de manera relevante en la discusión pública desde 1940 y hasta la llegada de la dictadura ${ }^{35}$. Sin abogar necesariamente por la versión que señala que la dictadura simplemente vino a profundizar lo que ya estaba presente en la lógica de las instituciones sanitarias y en el ideario de la clase política dominante de la época, lo cierto es que llama la atención la tranquilidad con que se ha mantenido un sistema de salud eminentemente injusto ${ }^{36}$, sobre todo teniendo como base una Constitución que, a diferencia de la anterior, entiende la protección de la salud como un derecho socia ${ }^{37}$.

Nuestra Constitución consagra un derecho social a la protección de la salud en su artículo $19 \mathrm{~N}^{\circ} 9$ de la Constitución. Por eso, esta segunda parte del artículo pretende descartar lo que parte de la doctrina ha consagrado como el discurso hegemónico de lo que dicha disposición exige Apoyados en la seguridad de que la Constitución de 1980 consagraba un proyecto político neoliberal en lo económico algunos constitucionalistas han pretendido ver en esta disposición 1) una garantía de protección de un mínimo de salud para quienes no pueden pagar por ella que a la vez, 2) consagra y protege un sistema privado de salud que permite a toda persona (que pueda) acceder al mercado para comprar seguros de salud individuales 3) y que, con este objeto, permite a la ley establecer cotizaciones obligatorias, las cuales deben ir favor exclusivo del destinatario. En térmi-

35 En efecto, si se observa la historia de las instituciones sanitarias y la discusión pública entre 1924 y 1973 se puede observar cómo progresivamente se fue ampliando el derecho a recibir prestaciones médicas. Primero las prestaciones eran exclusivamente para los trabajadores que cotizaban (el derecho a recibir prestaciones tenía un fundamento bastante utilitarista: el cuidado del capital humano, el cuidado del trabajo como fuerza productiva). Poco a poco la cobertura se fue ampliando a diversos grupos, hasta la llegada del Servicio Nacional de Salud en 1952. El Servicio Nacional de Salud representó un hito en la historia de la salud en Chile, ya que reunió en su seno los principales servicios de salud, desperdigados bajo el alero de distintas instituciones: los hospitales administrados por la Junta de Beneficencia, los consultorios de la Caja del Seguro, la Dirección de Sanidad y otras instituciones especializadas en ciertas materias. De alguna forma el SNS fue planteado como un proyecto fundacional, pero incompleto, porque su cobertura no era universal y la idea era avanzar en ese camino de modo gradual. En efecto, como el SNS nació como un proyecto incompleto que debía avanzar progresivamente hacia la protección sanitaria de toda la población, la lucha entre el avance de dicho proyecto y su restricción permaneció vigente hasta 1973. Sobre este tema véanse los interesantes artículos de (i) Molina, Carlos Antonio ( ) "Antecedentes del Servicio Nacional de Salud. Historia de debates y contradicciones. Chile 1932-1952". Cuadernos Médico Sociales, Vol. 46, N 4, pp. 284-304 y ( ) "La ley de Medicina Curativa. Un análisis histórico de sus antecedentes y efectos en la institucionalidad sanitaria en Chile”. Cuadernos Médico Sociales, Vol. 46, N 1, pp. 74-100; (ii) Labra, María Elena (2004). "Medicina Social en Chile: Propuestas y Debates (1920-1950)". Cuadernos Médico Sociales, Vol. 44, N 4, pp. 207-219.

36 Que se haya mantenido no implica que no hayan sido impugnados algunos aspectos del mismo. Al respecto véase el sinnúmero de recursos de protección y acciones de inaplicabilidad acogidos por los tribunales.

37 La Constitución de 1925 establecía en el último inciso del artículo $10 \mathrm{~N}^{\circ} 14$. El desarrollo del derecho a la salud operó entonces por la vía legislativa y reglamentaria hasta 1973. 
nos simples, la Constitución garantizaría la libertad para que cada individuo pueda acceder a prestaciones de salud sujetas a las reglas del contrato y un sistema público de salud para quienes no son capaces de contratar en el mercado.

Pero no solo quienes han buscado proteger el sistema de salud actual han hecho dicha interpretación constitucional del artículo $19 \mathrm{~N}^{\circ}$ 9. También constitucionalistas como Alejandra Zúniga han señalado que se trata de un derecho individual más que social ya que "Desde el punto de vista constitucional, entonces, puede sostenerse que se contempla a la atención sanitaria solo como un derecho negativo que implica la mera libertad de adquirir asistencia en el mercado de la protección de la salud, puesto que el único inciso que está garantizado judicialmente es aquel que reconoce el derecho a 'elegir el sistema de salud al que desee acogerse, sea este estatal o privado'. Ello implica que el constituyente ha priorizado, sobre la consideración de la necesidad de atención médica, a la capacidad de pago como único fundamento para acceder a los recursos sanitarios, lo que, según vimos, contraría las pretensiones de equidad fundamentadas por el liberalismo igualitario" 38 . Es un error, no obstante, creer que la Constitución solo permite la existencia de un sistema sanitario como el actual. Como se verá en esta parte, una correcta interpretación constitucional del artículo 19 No 9 muestra que éste es compatible con un sistema sanitario organizado como un seguro social universal.

\section{1) El SISTEMA DE SALUD ACTUAL}

El sistema actual de salud chileno se estructura precisamente sobre la base de estas ideas. En breve, se trata de un sistema dual público y privado $^{39}$. Bajo este sistema las personas están obligadas a destinar el 7\% de sus remuneraciones al financiamiento de la salud (lo que se denomina cotización). En términos teóricos, la Constitución permite a las personas elegir entre destinar las cotizaciones a contratar los seguros privados de salud que ofrecen las Instituciones de Salud Previsional (Isapre) o destinarlas a financiar un fondo de salud público (Fonasa) que cubre las prestaciones de salud pública que el Estado otorga a todas las personas que no tienen ingresos o que sus remuneraciones no les permiten contratar los seguros privados que las Isapre ofrecen en el mercado.

38 ZúNíga, Alejandra (2010) "Una teoría de la justicia para el cuidado sanitario: la protección de la salud en la Constitución después de la reforma AUGE”. Revista de Derecho, Vol XXIII, $\mathrm{N}^{\circ}$ 2, diciembre, pp. 113-130. Disponible en http://www.scielo.cl/pdf/revider/v23n2/art06. pdf [fecha de visita 1 de septiembre de 2014], p. 124.

39 El sistema fue creado en 1981 (en la misma etapa en que se comenzaba a dar forma a nuevo modelo educativo y un nuevo sistema de pensiones), a través del Decreto con Fuerza de Ley $\mathrm{N}^{\circ} 3$ que "fija normas para el otorgamiento de prestaciones y beneficios de salud, por instituciones de salud previsional". 
Como se ve, nuestro sistema funciona bajo dos lógicas distintas: una de seguros social (o de servicio público) y otra de mercado. Bajo el subsistema de salud público las cotizaciones que pagan las personas operan de manera similar a los impuestos solo que su destino está determinado a un fin especial: cubrir las prestaciones de salud de la población incapaz de contratar con las aseguradoras. Es así como el sistema público recibe al sector de la población más riesgoso y de los quintiles más bajos (ya que tiene la obligación de recibirlos). Por su parte, los más ricos y menos riesgosos aseguran sus riesgos a través de contratos privados con las Isapre, ya que la ley les permite destinar sus cotizaciones a dicho pago. Es así como bajo el subsistema de salud privado las cotizaciones pierden su carácter social por la vía de destinarlas a la contratación de un seguro privado que opera sobre la base de los riesgos individuales ${ }^{40}$ : para el $16 \%$ de la población las cotizaciones no funcionan como impuestos sino que como precios, frente a la obligación legal de contratar un seguro privado.

\section{2) EL DERECHO A LA PROTECCIÓN DE LA SALUD Y SU INTERPRETACIÓN DOMINANTE. ENTRE EL ORIGINALISMO Y EL FINALISMO}

Es un lugar común afirmar que el sistema institucional de salud chileno encuentra su consagración en la Constitución, la cual además no admitiría otro sistema sanitario alternativo ${ }^{41}$. Eso es un error.

La Constitución consagra en el artículo $19 \mathrm{~N}^{\circ}$ 9, para todas las personas, el derecho a la protección de la salud. Como concreción de esa idea, la Constitución establece que "el Estado debe proteger el libre e igualitario acceso a las acciones de promoción, protección y recuperación de la salud $y$ de rehabilitación del individuo". Esto implica que toda persona tiene libertad para acceder a las prestaciones de salud, acceso que por supuesto, no constituye un deber para el paciente. Más relevante, sin embargo, es la garantía de acceso igualitario a dichas prestaciones, sobre la cual la doctrina constitucional no se ha pronunciado.

40 Como se trata de seguros privados, sujetos por tanto a las reglas del mercado, las mujeres en edad fértil y los más viejos son los que deben pagar las primas más altas ya que son los más costosos.

41 Bulnes, Luz (2001) "El derecho a la protección de la salud en la Constitución de 1980". Actualidad Juridica: La Revista de Derecho de la Universidad del Desarrollo. Año II, No 4, pp. 131-148. CeA, José Luis (2004) Derecho Constitucional Chileno: Derechos, deberes y garantías. Tomo II. Santiago: Ediciones UC, 733 pp.; Vivanco, Ángela (2010) "Justicia constitucional, libre elección en materia de salud y normativa sobre Isapres: un comentario a la reciente normativa del Tribunal Constitucional". Revista Chilena de Derecho, Vol 37, $\mathrm{N}^{\circ} 1$ pp. 141-162. Disponible en http://www.scielo.cl/scielo.php?script=sci_arttext\&pid=S071834372010000100007[fecha de visita 1 de septiembre de 2014]. 
¿Qué quiere decir la Constitución cuando dispone que el Estado debe proteger el acceso igualitario a las prestaciones de salud? Mi idea es que un acceso igualitario exige eliminar la duplicidad de sistemas público y de seguros privados tal como existe hoy en día en favor de un sistema de seguros social universal.

La disposición constitucional no obstante, no se conforma con dicha garantía, sino que sienta las bases de cómo debe estructurarse un sistema de "libre e igualitario acceso" a las prestaciones de salud. Con este objetivo, la Constitución señala que "es deber preferente del Estado garantizar la ejecución de las acciones de salud, sea que se presten a través de instituciones públicas o privadas, en la forma y condiciones que determine la ley, la que podrá establecer cotizaciones obligatorias" ${ }^{2}$, estableciendo a continuación el "derecho a elegir el sistema de salud al que desee acogerse, sea este estatal o privado" 43 .

Parte de la doctrina ha leído en esta parte de la disposición una decisión constitucional sobre la forma institucional que necesariamente ha de tomar sistema de salud, decisión que consistiría en que el Estado tiene el deber de garantizar, además de un sistema público que otorgue un mínimo necesario, una institucionalidad privada que funcione en el mercado. Bajo esta lectura, la Constitución obligaría al legislador a proteger el actual sistema de salud y en especial, el sistema privado que opera a través de las Isapre y que se mantiene gracias a que las cotizaciones obligatorias pueden destinarse a la contratación de seguros privados.

Es así como estos profesores han hecho equivalentes la disposición constitucional y la regulación legal del sistema de Isapre por la vía de afirmar que el inciso final del artículo $19 \mathrm{~N}^{\circ} 9$ establece el marco del modelo de salud existente en Chile ${ }^{44}$. Desde esta perspectiva, pareciera que no existe libertad para que el legislador decida un sistema distinto. Sin embargo, aunque esa lectura pudo haber sido en gran parte de la intención de la Comisión Ortúzar ${ }^{45}$, es incorrecto en general equiparar la intención

42 Al igual que sucede con el derecho a la protección de la salud, el derecho a la seguridad social contemplado en el artículo $19 \mathrm{~N}^{\circ} 18$ también establece que "la ley podrá establecer cotizaciones obligatorias".

43 Esta disposición es la única que se encuentra protegida por el recurso de protección y es la que ha dado la oportunidad de reclamos de particulares a través del recurso de protección y por vía consecuencial ha permitido interponer acciones de inaplicabilidad por inconstitucionalidad. En este contexto el TC declaró en el año 2009 la inconstitucionalidad de la disposición de la ley de Isapre (art. 38 ter L18933) que establecía la posibilidad de fijar los precios de los planes tomando en consideración el sexo y la edad.

44 Vivanco (2010).

45 Así, por ejemplo Vivanco apela el derecho a la protección de la salud "está circunscrito en la posibilidad de ser satisfecho en plenitud por la capacidad económica del Estado, siempre limitada; pone en juego la obligación del Estado de actuar en forma dinámica y prioritaria entre sus preocupaciones dentro de este campo, y al mismo tiempo exige una armonización entre ese deber del Estado, que es prioritario entre sus deberes, y el derecho a los ciudadanos de participar como particulares en la actividad determinada, derecho que es preferente, in- 
del constituyente con el sentido que pudiere atribuirse a disposiciones constitucionales y en particular a la que asegura a todas las personas el derecho a la protección de la salud ${ }^{46}$. El problema con las interpretaciones originalistas y en el que caen quienes apelan a ellas en Chile es que quienes las utilizan entienden la intención originaria como las intenciones específicas y concretas que los redactores pudieron haber tenido respecto a algún tema particular, cuando lo correcto en tanto interpretación es que el sentido que hay que atribuir a la intención originaria es la mejor versión de la idea abstracta que le subyacía ${ }^{47}$.

La doctrina, no obstante, ha tenido que recurrir a una interpretación no solo originalista, sino que también desapegada del texto de la disposición en la medida en que una interpretación ceñida a su tenor no conduce a las conclusiones de más arriba. En efecto, las interpretaciones finalistas también han estado disponibles a la hora de atribuir sentido a las disposiciones constitucionales ${ }^{48}$.

Sin embargo, el texto de la disposición $19 \mathrm{~N}^{\circ} 9$ de la Constitución no exige una estructura sanitaria de tal como la que configura el régimen legal actual. En efecto, la Constitución no obliga al legislador a que mantenga un sistema privado de seguros individuales financiado por quienes pueden y un sistema público para el restante de la población que no puede pagar el precio de dichos seguros ${ }^{49}$.

\section{3) LA INTERPRETACIÓN POSIBLE DEL DERECHO A LA PROTECCIÓN DE LA SALUD}

A este respecto, dos interpretaciones son posibles a la luz del texto de la disposición contenida en el artículo $19 \mathrm{~N}^{\circ} 9$ de la Constitución.

\subsection{1) El sistema privado y la inexistencia del deber de fomentarlo}

Bajo una primera interpretación es posible afirmar que en ningún lugar la disposición contempla un mandato de fomento o mantenimiento de un

cluso desde el punto de vista de la libertad, a la acción del Estado, acción que en este sentido, adquiere un carácter subsidiario

46 Es interesante ver cómo esta doctrina constitucional que se apoya en una interpretación originalista de la constitución en materia de salud es la misma que otras veces se niega a hacer de esta interpretación (como en el caso del derecho a la vida y el aborto).

47 Dworkin, Ronald (1986) A matter of principle. Oxford: Clarendon Press, 425 pp., p. 57 , donde discute sobre las teorías interpretativas originalistas y señala que: "The important question for constitutional theory is not whether the intention of those who made de Constitution should count, but rather what should count as the intention".

48 Las interpretaciones finalistas han aparecido por ejemplo, a la hora de interpretar el derecho a la vida (19 No 1) o el derecho a la libertad de empresa (19 No 21).

49 Por lo demás, cabe señalar que el sistema de salud actual no existía en la época en que se aprobó la Constitución. Casi un año después, en mayo de 1981, el DFL Nº 3 daría inicio a la creación de las Instituciones de Salud Previsional. 
sistema privado de salud que opere paralelamente al sistema público. El hecho de que la norma seńale que "es deber preferente del Estado garantizar la ejecución de las acciones de salud, sea que se presten a través de instituciones públicas o privadas" o que las personas tienen "derecho a elegir el sistema de salud al que desee acogerse, sea este estatal o privado" no significa que el Estado tenga el deber de fomentar el sistema privado ya sea a través de subsidios o de regulaciones legales que permitan a las personas destinarle sus cotizaciones obligatorias. El sistema privado es privado y si bien el Estado no puede prohibir dicho sistema no está obligado a financiarlo.

Bajo esta interpretación, la Constitución permitiría el funcionamiento de un mercado de la salud más o menos como el actual, el punto es que el Estado no tendría ningún deber de destinarle cotizaciones o subsidios: las personas tendrían que financiar sus seguros privados o sus prestaciones sanitarias con dineros adicionales a los de sus cotizaciones, las cuales irían a financiar el sistema de salud universal.

Frente a esto, podría señalarse que la frase final del artículo $19 \mathrm{~N}^{\circ} 9$ que protege el "derecho a elegir el sistema de salud al que desee acogerse, sea este estatal o privado" tiene por objeto asegurar la necesaria existencia de oferta privada de seguros individuales privados. Es interesante que en base a dichas palabras algunos pudieren justificar un deber del Estado de garantizar la existencia de las Isapre. Tal interpretación utiliza el "derecho a elegir" un sistema estatal o privado como una forma de asegurar la existencia de la oferta privada, ya que si desaparecen las Isapre (sea por falta de financiamiento o por falta de incentivos económicos) las personas no podrían elegir acogerse a ellas y el Estado, por tanto, no estaría garantizando el "derecho a elegir" de las personas.

Aunque persuasivo, dicho argumento es incorrecto toda vez que deriva de una "libertad" un "deber" para el Estado de aseguramiento de la oferta privada. Sin embargo, a diferencia de lo que ocurre con los "derechos", cuyos correlativos jurídicos establecen "deberes" para las personas que se encuentran frente al titular del derecho; las libertades no imponen deberes a nadie como correlato: ni al Estado ni menos a los particulares ${ }^{50}$. El correlato jurídico de las libertades no es el deber de otros (no es el deber de no interferir con mi libertad) sino simplemente el establecimiento de un "no derecho": frente a la libertad, los otros no tienen el derecho de prohibirme su ejercicio y por esta vía, por ejemplo, obligarme a suscribir un sistema de salud determinado. Así, una libertad no obliga a otros a realizar las acciones necesarias para hacer efectiva mi libertad, sino que más bien garantiza que el Estado en términos del artículo $19 \mathrm{~N}^{\circ}$ 9, no prohibirá a las personas elegir un sistema de salud, o en otros términos, no impondrá a las personas el deber de sujetarse a ningún sistema en par-

50 Hohfeld, Wesley Newcomb (2001) Conceptos Juridicos Fundamentales. México: Fontamara, pp. $45-87$. 
ticular $^{51}$. La libertad es lo opuesto al deber, y por tanto una libertad de elegir impide imponer un deber de afiliación concreta.

Por otra parte si se tratara ya no solo de una libertad a secas, sino de un derecho a elegir, es decir, de una estructura configurada como una libertad protegida por un derecho, tenemos la siguiente situación ${ }^{52}$ : la Constitución consagraría el "derecho" de todas las personas a elegir. Todas las personas son titulares de este derecho, por lo que el Estado tendría el deber de garantizar no solo que puedan hacerlo quienes cuentan con ingresos altos, sino que también puedan hacerlo quienes obtienen ingresos medios, bajos e incluso quienes no obtienen ingresos del todo.

Esto significa que el Estado tendría el deber configurar un sistema sanitario que permita a todos elegir, ya que como se sabe, el sistema actual solo permite dicha elección al $10 \%$ más rico de la población ${ }^{53}$. Para el cumplimiento de este deber correlativo al derecho de cada uno, el Estado tendría que modificar el sistema sanitario actual en aspectos importantes, de manera tal de hacer posible que todos pudieran elegir entre un sistema público y uno privado de salud. Una forma de hacer esto sería a través del establecimiento de un "plan único de salud" que tanto el Estado como los privados tendrían que ofrecer a todos, sin posibilidad de excluir en la medida en que bajo esta interpretación es deber del Estado realizar la libertad de todos.

Dicho plan único sería financiado por el Estado de un fondo que estaría conformado por las cotizaciones de todas las personas y por recursos fiscales adicionales.

\subsection{2) Los privados como colaboradores del Estado}

La segunda interpretación se afirma en que, del hecho que la Constitución deje un espacio para que los privados intervengan en el ámbito de la salud no puede deducirse que dicho espacio sea de absoluta libertad: la Constitución no garantiza que el sistema privado de salud tenga que operar bajo la misma estructura con que operan hoy las Isapre. De hecho, una interpretación coherente y armónica con el conjunto de los incisos del artículo $19 \mathrm{~N}^{\circ} 9$ nos debiera llevar a entender que la participación de los privados en el ámbito de la salud requiere estar sometida a intensas restricciones, las que debieran estar orientadas a hacer que sea más o me-

51 En este sentido, la libertad de emprendimiento no implica prohibir, por ejemplo, la competencia, es decir, no implica un deber de abstención para que el titular de la libertad pueda efectivamente gozar de la misma.

52 Alexy (1993) 210-27.

53 Según las estadísticas de la Superintendencia de Salud, en el sistema de Isapre a noviembre de 2013, 1.723 .706 es el número de cotizantes y 1.470.037 el número de cargas. Sumados ambos números, podemos decir que solo el $20 \%$ de la población es beneficiaria de dicho sistema. 
nos indiferente para las personas que las prestaciones de salud se realicen por el Estado o por los privados.

Un ejemplo del tipo de regulaciones a las que tendría que estar sujeta la participación privada es que le estaría prohibido cobrar y excluir. En esta interpretación el espacio de los privados sería el de colaboradores del Estado en la protección de la salud: su participación se realizaría otorgando prestaciones sanitarias bajo un régimen similar al del Estado, es decir, bajo un régimen público ${ }^{54}$.

Esta interpretación adquiere su fuerza cuando se observa que el artículo $19 \mathrm{~N}^{\circ} 9$ señala que es "deber preferente del Estado garantizar la ejecución de las acciones de salud, sea que se presten a través de instituciones públicas o privadas". La idea dominante de la disposición transcrita es que Estado tiene el deber de garantizar que se ejecuten las acciones de salud sea quien sea la entidad que las preste. Es sobre la base de dicho rol garantizador del Estado que este tiene el deber imponer a los privados reglas propias de un régimen de servicio público: sin importar quién realice las prestaciones sanitarias, el Estado tiene la responsabilidad de garantizar su efectiva prestación. Bajo esta lógica, los agentes privados actuarían como colaboradores del Estado quien tiene el deber de garantizar que sus prestaciones se sujeten a los estándares que sean necesarios para que todos puedan acceder a prestaciones sanitarias adecuadas.

En este sentido es interesante la interpretación que ha tenido la jurisprudencia constitucional en relación a las Isapre y sus seguros privados. El Tribunal Constitucional, por ejemplo, ha señalado que las Isapre ostentan la naturaleza de "servicio público desarrollado por particulares cuyo giro es cubrir las acciones de salud contenidas en la Constitución Politica de la República" ${ }^{55}$. Esta imputación de que las Isapre serían un servicio público no deja de ser importante, porque de alguna forma lo que se está haciendo es imponer a un privado obligaciones más allá de las establecidas en la ley en razón de que las Isapre, aunque son privados, realizarían una actividad de servicio público, es decir, una actividad que implicaría la entrega de prestaciones para la satisfacción de una necesidad de interés general. En otro tiempo, la jurisprudencia francesa construyó la doctrina de los "servicios públicos virtuales", identificando actividades prestadas por privados y no configuradas legalmente como servicios públicos, pero pese a esto, actividades con un marcado carácter de interés general, con el objeto de extender obligaciones de servicio público con prescindencia de la ley.

\footnotetext{
54 Esta idea de "régimen público" o "régimen de lo público" y sus características ha sido uno de los grandes aportes, en el interesante libro de Atria, Fernando; et al. (2013) El Otro Modelo. Santiago: RandomHouse, 383 pp.

55 STC Rol 1856-2010, considerando 11. También se refiere a la idea de servicio público en los considerandos 13 y 34 .
} 
Esto es consistente con la razón que subyace a los fallos de las Cortes de Apelaciones y la Corte Suprema cuando acogen los innumerables recursos de protección contra las Isapre por alza unilateral de los precios, señalando que de esta forma las Isapre actuarían "arbitrariamente". La prohibición de arbitrariedad es una prohibición adecuada para los órganos del Estado: es eminentemente el Estado, y no los privados quien está interdicto para actuar arbitrariamente. Los particulares, por el contrario, pueden hacerlo: sus actos no requieren de fundamentos ni de razonabilidad, en principio. De esta forma, declarar arbitrarias las alzas de los planes que realizan las Isapre, las Cortes están asumiendo, implícitamente, que se trata de entidades que no se rigen completamente por el derecho común sino que están sujetas en su actuar a un régimen especial, similar al régimen al que se sujeta la administración pública.

De acuerdo a esta interpretación, la intervención a través de la creación de un régimen público no solo estaría autorizada por la Constitución sino que vendría exigida por la obligación estatal de garantizar la ejecución de las prestaciones sanitarias. En este sentido, las Isapre serían servicios públicos impropios o virtuales, es decir, pese a ser entidades privadas realizarían funciones de servicio público. Como tales, las Isapre podrían participar en la prestación de servicios sanitarios, pero siempre sometidas a un régimen público que de esta forma garantizase de forma efectiva el derecho social de todos a un "libre e igualitario acceso a las acciones de promoción, protección y recuperación de la salud y de rehabilitación". Dicho régimen público, no podría excluir a ninguna persona por ninguna circunstancia (ya sea por edad, riesgo, capacidad económica, entre otras), tal como el régimen público de gestión estatal funciona hoy. Esto, por supuesto, obligaría a reconfigurar el sistema de salud actual, cuyo aspecto privado está eminentemente sometido al régimen de mercado y no a un régimen público. La idea de que la Constitución asegura a los particulares la posibilidad de que la prestación de los servicios relacionados a derechos sociales pueda estructurarse exclusivamente como un mercado privado es incorrecta. Cuando la Constitución consagra la actividad de los privados no lo hace estableciendo un mercado sino que asegurando su participación, la cual podría asumir variadas formas, más o menos colaborativas.

A este respecto, debe observarse que el derecho a la protección de la salud no tiene como complemento un derecho o libertad análogo a lo que es la libertad de enseñanza en materia educativa, que permitiera concluir que en algún sentido relevante existe un deber de abstención del Estado frente a la libre configuración de actividades sanitarias privadas ${ }^{56}$. En

56 En este punto ilustrativa la historia de la privatización de los servicios sociales durante la dictadura. Aparejada a la privatización de la salud y la previsión el gobierno militar decidió crear una superintendencia de AFP y una Superintendencia de Isapre. La privatización de la educación no llevó aparejada la creación de una superintendencia. Esta diferencia no se 
todo caso, la libertad de enseñanza que la Constitución asegura no solo no es incompatible con un régimen educativo que prohíba la exclusión, sino que más bien la requiere, desde el momento es que esta libertad debe ser compatible con el derecho a la educación ${ }^{57}$.

Finalmente, esta última interpretación en la cual los privados actuarían como colaboradores, es consistente con el "derecho a elegir" un sistema de salud "sea estatal o privado" que la Constitución garantiza. Cabe señalar que esa libertad que la Constitución asegura a las personas es un límite para todo ideario que pretenda estructurar un sistema públicoestatal de salud que impida de manera directa que los agentes privados cumplan algún rol en materia de salud, ya sea como colaboradores, como esta interpretación plantea, ya sea subsidiariamente como la primera interpretación propone. Bajo los términos actuales del artículo $19 \mathrm{~N}^{\circ} 9$ de la Constitución, los particulares tienen un espacio, aunque no necesariamente el que les entrega el sistema actual.

Ahora bien, uno podría preguntarse si el rol colaborador de los agentes privados requiere que estos no puedan lucrar con sus servicios. Esto vale para las dos interpretaciones propuestas. Sin embargo y a riesgo de malentendidos, antes de responder esta pregunta conviene hacer una precisión: la idea de lucro, en estos términos, se refiere a la posibilidad de la salud como un negocio y no a que las personas que laboren en estos ámbitos obtengan una debida remuneración por la prestación de sus servicios. El lucro con la salud implica la posibilidad de obtener rentas del capital, no del trabajo; por lo que en este sentido

La salud comenzó a ser un negocio en Chile, en el sentido de la posibilidad de acumulación de utilidades, solo con las reformas legales que se introdujeron en Chile a partir de 1980. Antes, si bien existía la medicina privada, este no era un negocio: el médico se remuneraba por la prestación de sus servicios, no por los rendimientos del capital.

Según algunos, del hecho que la Constitución no solo autorice sino que proteja la existencia de un sistema privado de salud, debe concluirse que a la vez garantiza la posibilidad de que dicho sistema se organice como un negocio. Esta interpretación, sin embargo, debe ser rechazada. La Constitución es silenciosa en este punto, por lo que dicha posibilidad debe decidirse en sede legislativa tal como sucede en materia educativa en relación a las Universidades.

Algunos señalan que la libertad económica consagrada en el artículo $19 \mathrm{~N}^{\circ} 21$ garantiza que incluso la prestación de servicios sociales como educación, salud y previsión se realice en los mismos términos que cual-

entiende sino sobre la base de que se entendía que podía eventualmente ser riesgoso para la libertad de enseñanza (y de proyectos educativos) la existencia de una entidad fiscalizadora, cuestión que no sucedía en el caso de las Isapre o las AFP.

57 Véase Atria, Fernando (2007) Mercado y Ciudadania. Santiago: Flandes Indiano, 126 pp. 
quier otra actividad económica. Eso no es correcto en la medida en que la Constitución asegura no solo la libertad económica en el $19 \mathrm{~N}^{\circ} 21$, sino también derechos sociales, como el derecho a la salud, la educación y la previsión. De hecho los artículos $19 \mathrm{~N}^{\circ} 9,19 \mathrm{~N}^{\circ} 11$ y $19 \mathrm{~N}^{\circ} 18$, que consagran los derechos sociales antes señalados, respectivamente, establecen al mismo tiempo un espacio para la actividad o la iniciativa de las personas, sin establecer que el emprendimiento de dichas actividades que presten servicios sociales tenga por objeto enriquecer a quienes lo hacen.

No obstante lo anterior, lo relevante en el derecho a la protección de la salud como derecho, no se define por si existe o no la posibilidad de lucro, sino que se define por el régimen público que garantice el "libre e igualitario acceso" a las prestaciones de salud. Que las instituciones privadas lucren o puedan apropiarse a título de utilidades parte de los fondos que les transfiera el Estado por sus prestaciones no es definitorio del derecho a la salud. En la medida en que la ganancia fuera el único motor para que los particulares participaran como colaboradores y su actuación fuese necesaria o importante, no habría problema con asegurarles un margen de utilidades previamente definido o al menos permitirles dicho margen como máximo, a su propio riesgo.

\subsection{3) Las cotizaciones y su destino público}

Una tercera cuestión relevante y que en gran parte se relaciona directamente con las interpretaciones que ya hemos visto, es si la Constitución determina que las cotizaciones que la ley establezca son de propiedad de los cotizantes.

Esta idea surgió en la discusión legislativa del proyecto de ley que terminó con la aprobación del denominado plan Auge ${ }^{58}$. La propuesta original del gobierno de la época ${ }^{59}$, básicamente, era la creación de un fondo de compensación solidario que establecía un conjunto de subsidios cruzados en función de riesgos, que por tanto integraba de manera limitada y restringida el sistema público con el privado. La consecuencia era que parte de las cotizaciones de quienes contrataban con las Isapre tendrían que destinarse a este fondo común. Esta idea, que iba en la línea correcta no llegó muy lejos ante el rechazo rotundo de algunos senadores de derecha ${ }^{60}$.

\footnotetext{
$58 \quad$ Ver la historia de la ley 19966.

59 Una reforma al sistema de salud era la gran reforma que el Presidente Lagos había ofrecido en su campańa. La idea era establecer un sistema de derechos y garantías para las personas sobre la base de un esquema de financiamiento solidario.

La historia de cómo se gestó el proyecto de reforma concreto al interior del gobierno (antes de ser presentado al Congreso) es bastante interesante, porque fue objetado por la DC y hubo de ser modificada la idea original con el objeto de contar con su apoyo.

60

Probablemente no se luchó más por la idea debido a que al interior de la coalición de centro izquierda no existía un férreo apoyo de parte de la Democracia Cristiana respecto a este
} 
Los argumentos que llevaron a su rechazo muestran la instrumentalización de la interpretación de la Constitución, la cual se ha usado para defender un sistema neoliberal incluso ahí donde el expreso tenor literal de la misma es absolutamente silencioso sobre el carácter del sistema. Si se observa, el inciso final del artículo $19 \mathrm{~N}^{\circ} 9$ solo señala, de forma lapidaria, que para garantizar la ejecución de las acciones de salud, la ley "podrá establecer cotizaciones obligatorias".

Sin embargo, en relación a este punto los parlamentarios representantes de la oposición al gobierno de la época señalaron que, desviar parte de la cotización a la formación del Fondo de Compensación Solidario puede adolecer también de inconstitucionalidad, en la medida en que se priva a los cotizantes de una parte de la cotización que les pertenece ${ }^{61} \mathrm{y}$ amenazaron que requerirían al tribunal constitucional ${ }^{62}$ fundando su reclamación en el hecho de que el Fondo se financia con las cotizaciones de salud, las que pertenecen al respectivo afiliado. Destinar una parte de las mismas a integrar el Fondo de Compensación Solidario implica el establecimiento de un impuesto encubierto, afecto a un fin específico, y constituye una flagrante violación del derecho de propiedad de cada afiliado respecto de sus propias cotizaciones de salud ${ }^{63}$.

$\mathrm{El}$ argumento ofrecido por los parlamentarios encuentra su sustento en la doctrina del profesor José Luis Cea, quien señala que:

Procede precisar que las cotizaciones son, más que ahorros forzosos de quien las hace, verdaderos tributos o cargas públicas reales en su sentido amplio. Además, debe tenerse presente que ellas ceden a favor exclusivo del beneficiario y de sus familiares legalmente reconocidos. Consecuentemente afirmamos que el 7\% de cotización obligatoria impuesta por la ley es patrimonio del cotizante respectivo, estando destinada a contribuir al financiamiento de las acciones de salud para él y sus familiares. Se trata, por consiguiente y sin duda, de un bien cuyo dominio o propiedad pertenece al cotizante. Por tal razón consideramos discutible el mérito constitucional de la idea, hasta hoy solo tal y no articulada en un proyecto de ley, que destina $3 \%$ de ese guarismo a un fondo común y solidario para el propósito referido. El titular de esa cotización tiene, insistimos, dominio pleno sobre la

punto. Esta información puede encontrarse en el trabajo de Lenz, Rony, "Proceso político de la reforma AUGE de salud en Chile: algunas lecciones para América Latina”, en Serie Estudios Socio / Económicos N³8, CIEPLAN, junio 2007.

61 Historia de la ley 19966, p. 472. En base a esa razón, el senador Alberto Espina señaló que: "En vista de las dudas sobre la constitucionalidad que pesan sobre los artículos del proyecto que regulan el Fondo de Compensación Solidario y la Prima Universal, anunció que se abstendría en la votación de los mismos y que parlamentarios de su sector recurrirán al Tribunal Constitucional para que dilucide estos puntos".

62 Artículo $82 \mathrm{~N}^{\circ} 2$ de la época, hoy $93 \mathrm{~N}^{\circ} 2$.

$63 \quad$ Historia de la ley 19966, p. 537. 
integridad de ella, siendo suyo también el derecho a destinarla al sistema de salud que elija, con entera libertad ${ }^{64}$.

Según Cea, las cotizaciones de salud son "tributos". El punto de Cea es completamente correcto si su objeto es mostrar que el hecho de que sean cotizaciones no impide considerarlas tributos; lo que sí, es que su establecimiento en el artículo $19 \mathrm{~N}^{\circ} 9$ lo que permite es excluirlas de la garantía de no afectación que el artículo $19 \mathrm{~N}^{\circ} 20$ inciso segundo establece ${ }^{65}$.

Lo que, sin embargo, no solo es incorrecto sino que inconsistente con la idea de "tributos" es afirmar que las cotizaciones que la ley está autorizada para establecer "ceden a favor exclusivo del beneficiario y de sus familiares legalmente reconocidos" 66 . La Constitución en ninguna parte de su texto señala que las cotizaciones son "patrimonio del cotizante respectivo" o que "su dominio o propiedad pertenece al cotizante": lamentablemente para el profesor Cea, la Constitución no formula la exigencia de que las cotizaciones deban ir en beneficio de quien cotiza. Si bien es cierto es que la regulación legal actual así lo establece en el caso de las cotizaciones para pagar seguros privados ${ }^{67}$, él sabe que esa regulación es contingente en la medida que no viene exigida por la Constitución ${ }^{68}$.

$\mathrm{Ni}$ el tenor literal ni el espíritu de la disposición permiten concluir algo así como que las cotizaciones pertenecen al cotizante y que por tanto

64 CEA (2004) 312.

65 El artículo $19 \mathrm{~N}^{\circ} 20$ consagra un principio esencial en materia tributaria: la no afectación de los tributos. De acuerdo a este principio la Constitución reconoce la vinculación entre cotización e impuestos: el artículo $19 \mathrm{~N}^{\circ} 9$ y $19 \mathrm{~N}^{\circ} 18$ otorga un permiso al legislador para establecer cotizaciones de carácter obligatorio que se destinen a financiar salud y previsión respectivamente, permiso necesario en la medida en que el numeral 20 establece el principio de no afectación de los tributos.

66 Como se señaló CEA no solo se equivoca en señalar que las cotizaciones, como tributos que son, pertenecen al cotizante, quien tendría un derecho de propiedad sobre ellas, sino que también se contradice, porque es parte de la lógica de los tributos que ningún particular puede reclamar propiedad sobre ellos, y cuando se trata de impuestos, quien paga no puede exigir que vayan en su exclusivo beneficio.

67 Debido a que nuestro sistema establece que las cotizaciones de salud (en el caso de las Isapre) y previsión van en exclusivo beneficio de quien cotiza, la OCDE no puede considerarlas como formando parte de la carga tributaria. La razón que impide sumar las cotizaciones es que estas, tal como están configuradas actualmente, no pueden ser consideradas impuestos en la medida en que constituyen o bien un ahorro individual obligatorio (en el caso de las cotizaciones en el sistema de AFP) o bien una forma de pago a las ISAPRE por contratos de seguros de salud privados. Cabe señalar que la seguridad social se financia, en la mayoría de los países de la OCDE, mediante impuestos, cuando en Chile en cambio se financia mediante cotizaciones privadas.

68 Efectivamente en Chile, las cotizaciones operan como precios, no como impuestos. De hecho esa es la razón por la cual, diferencia de lo que ocurre con otros países, la OCDE no incluye como parte de la carga impositiva las cotizaciones que en Chile se realizan por salud y previsión. La OCDE está en lo correcto al no incluirlas como carga tributaria en la medida en que con las cotizaciones, tal como se regulan en nuestra legislación, se está pagando por beneficios privados exclusivamente y no beneficios sociales para todos. 
no pueden. De hecho, las cotizaciones para la mayor parte de la población no operan como Cea señala que debiesen operar bajo su comprensión de la Constitución: las cotizaciones del que no tiene contrato con una Isapre contribuyen a financiar un sistema público solidario que beneficia a todos los que participan de él.

No hay por tanto en el artículo $19 \mathrm{~N}^{\circ} 9$ de la Constitución argumento alguno que permita afirmar que es inconstitucional el establecimiento de cotizaciones destinadas a financiar un seguro social. La Constitución autoriza al legislador a imponer a los individuos la obligación de cotizar y no hay razón por la cual no pueda disponer de un destino público. El único límite es que las cotizaciones que el legislador establezca deben contribuir a "garantizar la ejecución de las acciones de salud, sea que se presten a través de instituciones públicas o privadas". En esta medida, como se señaló, las cotizaciones sean para salud o previsión deben estar destinadas al financiamiento de dichas prestaciones y por tanto están excluidas del destino. Pero eso no significa que las mismas deban ir en exclusivo beneficio de quien las realiza: las cotizaciones pueden ir en beneficio de todos, tal como sucede cuando se trata de seguros sociales universales ${ }^{69}$.

Por esta razón, de la Constitución no se sigue que las personas tengan propiedad sobre sus cotizaciones y por tanto de su utilización. Bajo las interpretaciones ya vistas, las cotizaciones perfectamente pueden ir a un fondo común que luego se distribuya entre el sistema público y el privado en proporción a la extensión y al ámbito de participación de cada uno.

Por eso es incorrecta la posición de los parlamentarios. No obstante esto la posición su proposición primó en la discusión y la disposición que introducía el fondo de compensación solidario fue eliminada.

Una idea más falta por resaltar. De acuerdo a la lógica neoliberal actual, es absolutamente inconsistente por paternalista una cotización de carácter "individual” pero que a la vez sea "obligatoria”: ¿por qué el Estado tendría que intervenir obligando a las personas a destinar un porcentaje no menor de sus rentas a financiar seguros individuales de salud? Una cotización de carácter obligatorio solo es razonable cuando su destino es común; es el destino solidario de la cotización el que le da pleno sentido a su obligatoriedad.

En los términos de la Constitución es perfectamente posible el establecimiento de un seguro social universal que opere en base a un fondo común, formado por las cotizaciones de todos quienes trabajan remuneradamente. Sorprende que Cea y parlamentarios de derecha hayan sido incapaces de ver lo anterior, apresurándose a declarar que era inconstitucional cuando ni el tenor literal de la Constitución ni el sistema legal (la

69 En efecto, a diferencia de los seguros individuales en que cada uno contribuye en función a sus riesgos, cuando se trata de seguros sociales, todos aportan en función a su capacidad contributiva y, básicamente, cada uno recibe en atención a sus necesidades. Así, los seguros sociales lo que hacen es socializar ciertos riesgos como vejez, invalidez y enfermedad, entre todos. 
lógica de las cotizaciones bajo el sistema público de salud actual) permitían arribar a tal conclusión.

\section{CONCLUSIONES}

El sistema actual de salud ha estado protegido por una interpretación constitucional que, sin atenerse al texto de la disposición del artículo 19 $\mathrm{N}^{\circ}$ 9, ha constitucionalizado un régimen neoliberal de derechos sociales rechazando como contraria a la Constitución toda idea que atente contra dicho régimen ${ }^{70}$. Hoy en día esta interpretación se ha vuelto dominante, alcanzando a constitucionalistas que no celebran sino que lamentan que la Constitución no tenga espacio más que para derechos individuales.

Como hemos visto, nuestra Constitución, pese a haber sido impuesta por la fuerza en plena dictadura, garantiza no solo libertades y mínimos sociales en materia de servicios sociales, sino que verdaderos derechos sociales. Esta parte ha mostrado que nuestra Constitución garantiza el derecho a la protección de la salud como derecho social, en la medida en que las dos interpretaciones propuestas no solo son compatibles con el texto constitucional sino que son su mejor interpretación a la luz del primer inciso del artículo $19 \mathrm{~N}^{\circ}$ 9, que señala que la Constitución segura a todas las personas "el derecho a la protección de la salud".

Ahora bien, un sistema dual de salud como el que existe hoy en día en Chile es un sistema que ofende y denigra el verdadero sentido de los derechos sociales y, en este caso, del derecho social a la protección de la salud. La razón de esta afirmación es que nuestro sistema de salud actual no es la institucionalización del derecho social a la protección de la salud del que todos somos titulares, sino simplemente la institucionalización del derecho a un mínimo necesario, derecho del que solo quienes carecen de recursos suficientes son titulares.

\section{BIBLIOGRAFÍA}

- Aвrahimovich, Víctor; Courtis, Christian (2002) Los derechos sociales como derechos exigibles. Madrid: Trotta, $254 \mathrm{pp}$.

- Alexy, Robert (1993) Teoría de los Derechos Fundamentales. Madrid: Centro de Estudios Constitucionales, 607 pp.

- Arriagada, María Beatriz (2012) "Los derechos sociales: únicos derechos fundamentales". En Aguilar, Gonzalo (editor): Los derechos

\footnotetext{
70 Algo similar ha pasado con lo que la doctrina ha llamado el "principio de subsidiariedad" y con el derecho a la educación y la libertad de enseñanza.
} 
Económicos, Sociales y Culturales en el orden constitucional chileno. Santiago: Librotecnia, pp. 61-91

- Atria, Fernando (2004) “Existen derechos sociales?", pp. 15-59, 4 Discusiones. Disponible en http://www.cervantesvirtual.com/obra/ existen-derechos-sociales-0/ [fecha de visita 1 de septiembre de 2014].

- Atria, Fernando (2007) Mercado y Ciudadanía. Santiago: Flandes Indiano, $126 \mathrm{pp}$.

- Atria, Fernando; et al. (2013) El Otro Modelo. Santiago: RandomHouse, 383 pp.

- Bulnes, Luz (2001) "El derecho a la protección de la salud en la Constitución de 1980". Actualidad Jurídica: La Revista de Derecho de la Universidad del Desarrollo. Ańo II, No 4, pp. 131-148.

- Bustos, Rodrigo (2009) "Derechos sociales y recurso de protección: ¿una relación difícil?”. Derecho y Humanidades, No 15, pp. 231-247.

- Cea, José Luis (2004) Derecho Constitucional Chileno: Derechos, deberes y garantias. Tomo II. Santiago: Ediciones UC, 733 pp.

- Daniel, Norman (2008) Just Health: Meeting Health Needs Fairly. New York: Cambridge University Press, 397 pp.

- Daniel, Norman; Kennedy, Bruce; Kawachi, Ichiro (1999) "Why justice is good to our health: the social determinants of health inequalities". Daedalus, Vol. 128, N ${ }^{\circ}$ 4, Bioethics and Beyond, pp. 215-251.

- Dworkin, Ronald (1986) A matter of principle. Oxford: Clarendon Press, 425 pp.

- Eleftheriadis, Pavlos (2012) "A Right to Health Care". The Journal of Law, Medicine and Ethics, Volume 40 Issue 2, Summer, pp. 268285.

- Figueroa, Rodolfo (2009) "Justificación del rol de las cortes haciendo justiciables los derechos económicos, sociales y culturales, en particular, el derecho a la protección de la salud". Revista Chilena de Derecho, vol. $36 \mathrm{~N}^{\circ}$ 2, pp. 313-342. Disponible en http://www.scielo.cl/scielo.php?script=sci_arttext\&pid $=$ S0718-34372009000200005 [fecha de visita 1 de septiembre de 2014].

- Hierro, Liborio (2009) "Los derechos económico-sociales y el principio de igualdad en la teoría de los derechos de Robert Alexy". Derechos Sociales y Ponderación. Madrid: Fundación Coloquio Jurídico Europeo, 405 pp.

- Hohfeld, Wesley Newcomb (2001) Conceptos Juridicos Fundamentales. México: Fontamara, pp. 45-87.

- Labra, María Elena (2004) "Medicina Social en Chile: Propuestas y Debates (1920-1950)". Cuadernos Médico Sociales, Vol. 44, № 4, pp. 207-219. 
- Marshall, Thomas Humphrey (1992) Ciudadanía y clase social. Madrid: Alianza Editorial, 149 pp.

- Michelon, Claudio (2004) "Introducción: derechos sociales y la dignidad de la igualdad", en 4 Discusiones, pp. 7-13. Disponible en http://www.cervantesvirtual.com/obra/introduccin-derechossociales-y-la-dignidad-de-la-igualdad-0/ [fecha de visita 1 de septiembre de 2014].

- Molina, Carlos A. "Antecedentes del Servicio Nacional de Salud. Historia de debates y contradicciones. Chile 1932-1952". Cuadernos Médico Sociales. Vol. 46, N 4.

- Molina, Carlos. A. "La ley de Medicina Curativa. Un análisis histórico de sus antecedentes y efectos en la institucionalidad sanitaria en Chile”. Cuadernos Médico Sociales. Vol. 46, N 1, pp. 74100.

- Ruiz Miguel, Alfonso (1994) "Derechos liberales y derechos sociales" (Doxa15-16), pp. 651-674. Disponible en http://www. cervantesvirtual.com/obra/derechos-liberales-y-derechos-sociales-0/ [fecha de visita 1 de septiembre de 2014].

- Singer, Peter (1972) "Famine, affluence, and morality". Philosophy and Public Affairs, Vol. 1, No 3 (Spring), pp. 229-243.

- Vivanco, Ángela (2010) "Justicia constitucional, libre elección en materia de salud y normativa sobre Isapres: un comentario a la reciente normativa del Tribunal Constitucional". Revista Chilena de Derecho, Vol. 37, $\mathrm{N}^{\circ} 1$.

- Weale, Alfred; Clark, Sarah (2012) "Social values in health priority setting: a conceptual framework". Journal of Health Organization and Management, Vol. 26, $\mathrm{N}^{\circ}$ 3, pp. 293-316.

- ZúñIgA, Alejandra (2010) "Una teoría de la justicia para el cuidado sanitario: la protección de la salud en la Constitución después de la reforma AUGE”. Revista de Derecho, Vol. XXIII, N ${ }^{\circ} 2$, diciembre, pp. 113-130. Disponible en http://www.scielo.cl/pdf/revider/v23n2/ art06.pdfffecha de visita 1 de septiembre de 2014].

- ZúÑigA, Alejandra (2009) "Más allá de la caridad". Revista de Derecho de la Pontificia Universidad Católica de Valparaíso, XXXIII, pp. 621-638. Disponible en http://www.scielo.cl/pdf/rdpucv/n33/ a17.pdf[fecha de visita 1 de septiembre de 2014]. 